\title{
Root Isolation for New Attachment Procedures
}

\section{A Surgical and Suturing Method: Three Case Reports}

\author{
William Becker, ${ }^{*}$ Burton E. Becker, John F. Prichard, \\ Raul Caffesse, $†$ Edwin Rosenbergł and Joseph Gian-Grasso§
}

Accepted for publication 4 March 1987

\begin{abstract}
A SURGICAL AND SUTURING METHOD Is described for the subgingival placement of Gore-tex ${ }^{\circledast}$ periodontal material during new attachment procedures. The periodontal material isolates the root surface from epithelium and gingival connective tissue. Three cases were treated. Clinical new attachment was evident from clinical probings and reentry. The term "open probing new attachment" describes the type of tissue that was evident at reentry after treatment of a Class III furcation. A combination of new bone and "open probing new attachment" was evident after one-wall defects were treated adjacent to a mandibular cuspid. A two-wall defect was treated and biopsied three months later. A reference notch was placed $1 \mathrm{~mm}$ coronal to the apical aspect of the defect. Histologic examination of the biopsy showed new bone, cementum and periodontal fibers coronal to the notch. Clinical and histologic new attachment was achieved using the technique for root isolation. The long-term predictability and stability of this type of new attachment is not known at this time.
\end{abstract}

A primary goal of periodontal therapy is regeneration of tissues that have been destroyed as a result of periodontal disease. Prichard ${ }^{1}$ believed that regeneration is prevented by rapid epithelialization of three wall defects. Various surgical procedures have been reported that attempt to exclude epithelium from proliferating along the root during healing. ${ }^{2,3}$

The cells necessary for new attachment are thought to originate from the periodontal membrane. ${ }^{4,5}$ During the past few years, a number of experimental studies have been undertaken in an effort to understand the biologic phenomenon of new attachment. The results from these studies indicate that when bone or gingival connective tissue contact the root surface, root resorption and ankylosis occur. ${ }^{6-8}$ When epithelium contacts the root, new attachment does not occur. ${ }^{9,10}$

Recently, experimental animals were used to investigate the principle of selective root repopulation. ${ }^{11-16}$ These studies used various types of filters and membranes to isolate root surfaces during new attachment

* Assistant Professor, University of Southern California, Department of Periodontics; Associate Professor, University of Michigan School of Dentistry, Department of Graduate Periodontics.

† Professor, University of Michigan School of Dentistry; Chairman, Department of Periodontics.

$\ddagger$ University of Pennsylvania School of Dental Medicine, Director of Postdoctoral Periodontics.

$\S$ Assistant Professor, Department of Periodontics, University of Pennsylvania School of Dental Medicine. procedures. They reported varying amounts of new attachment after analysis of histologic biopsies. The roots were presumably repopulated by cells from the periodontal membrane.

Nyman et al. ${ }^{17}$ placed a millipore filter between a root affected by periodontitis and the periodontal flap. The filter thus prevented gingival epithelium and connective tissue from contacting the root. New attachment was determined from histologic evaluation of the biopsied root and surrounding tissues. Gottlow et al. ${ }^{18}$ used the principle of guided tissue regeneration for treatment of furcation involvements and vertical defects. Isolation of root surfaces from adjacent tissues was accomplished by placing a supragingival teflon membrane between the root and periodontal flap. New attachment was documented from changes in probing attachment levels and defect depth and from biopsies of treated sites.

Supragingival membrane placement has the potential to create oral hygiene problems and may cause gingival recession. Furthermore, trauma from brushing may dislodge supragingival membranes and consequently interfere with new attachment formation.

The purpose of this pilot study is to present a surgical and suturing method for subgingival placement of occlusive periodontal material used to isolate the root during new attachment procedures. Three cases are presented. 


\section{MATERIALS AND METHODS}

The periodontal material used in this project is made from expanded polytetrafluoroethylene (E-PTFE), ${ }^{*}$ a biocompatible material not subject to biodestruction. The E-PTFE consists of two contiguous parts: an open microstructure collar that fits snugly against the tooth and an occlusive apron that isolates the root surfaces from the surrounding tissues.

Patients selected for this project were informed of the purpose of the study and were in good general health. Each patient signed a consent document and agreed to reentry procedures.

Just prior to the beginning of the study, patients had a complete periodontal and radiographic examination. Probing depths were taken from the gingival margin to the cementoenamel junction and from the cementoenamel junction to the base of the pocket. Six measurements were taken for each tooth and were used to determine gingival recession, probing depth and clinical attachment levels. Furcations were classified according to Glickman. ${ }^{19}$ Patients were provided one to three sessions of oral hygiene instruction and scaling and root planing. Occlusal adjustments were performed on teeth exhibiting fremitus or excessive mobility. Photographic documentation was accomplished at each visit.

Sites that were to receive the E-PTFE were remeasured the day of surgery. Patients were premedicated with intravenous medications, and the surgical field was locally anesthetized. Internal beveled incisions were begun one tooth distal to the tooth being treated and usually extended a minimum of two teeth anteriorly. Incisions were placed $0.5 \mathrm{~mm}$ apical to the free gingival margin. Vertical incisions were placed two teeth anterior to the tooth receiving the Gore-tex periodontal material. Buccal and lingual incisions were blended into the interdental areas in an attempt to preserve the interdental papillae. Moderately thick mucoperiosteal buccal lingual flaps were reflected past the mucogingival junction. Bony defects were debrided with hand curettes and files and the root surfaces debrided with ultrasonic and hand instruments. Roots were planed until they were smooth.

Furcations were measured as follows: horizontally at the fornix of the furcation, vertically at the midfurcation point on the cementoenamel junction to the interradicular alveolar crest, at the midfurcation point on the cementoenamel junction to the base of the defect, horizontally at the defect base, and the width of the defect base. Vertical defects were measured from the cementoenamel junction to the alveolar crest and from the cementoenamel junction to the defect base.

Prepackaged sterile E-PTFE periodontal material was placed on a sterile towel and trimmed to the approximate size needed to cover the root surface. The inferior

\footnotetext{
* Gore Periodontal Material, Gore-tex ${ }^{\circledR}$, W. L. Gore and Associates, Inc., Flagstaff, AZ.
}

border of the Gore-tex material was extended 3 to $4 \mathrm{~mm}$ apical to the inferior border of the bony defect and laterally to the mesial and distal interdental areas. The occlusal border of the material was placed $2 \mathrm{~mm}$ below the cementoenamel junction. The E-PTFE material was provisionally adapted to the root surfaces to ensure complete coverage of the defect and root surfaces. Final shaping of the material was accomplished with sharp scissors. The coronal open microstructure was not compressed during manipulation.

The suturing technique replaces the flap margin at or slightly coronal to its original position (Fig. 1). This is done to minimize postoperative recession. The distal border of the flap and E-PTFE were grasped apical to the collar with a corn suture forceps. $\dagger$ A 5-0 Dexon ${ }^{\circledR}$ suture was simultaneously passed through the oral aspect of the flap and E-PTFE and then through the interproximal space without engaging the lingual flap. Next, the suture was wrapped around the lingual side of the tooth and passed through the mesial lingual embrasure without penetrating the lingual flap. The suture was then passed through the mesial aspect of the flap and occlusive periodontal material, then through the mesial embrasure and wrapped around to the distal aspect of the tooth where it was passed through the embrasure. One throw of the suture was made and slight tension placed on it. At this stage, the flap must completely cover the material so that the final knot can be placed. If the E-PTFE is not covered, the flap must be resutured. After the continuous suture was completed, ${ }^{20} 4-0$ Dexon sutures were used to secure the interdental papillae. These sutures do not engage the occlusive material. Slight tension was placed on these sutures to achieve snug interproximal flap adaptation. Finally, interrupted sutures were used to close the vertical incisions. An alternative method of suturing can be used. ${ }^{21}$ The E-PTFE can be sutured directly around the tooth by a continuous sling suture. This method allows for visual inspection of adaptation of the Goretex periodontal material to the tooth. Interrupted sutures were then used for flap closure. Periodontal dressings were not used, and patients were requested not to use dental floss in the surgically treated area.

An antibiotic may be prescribed for seven days (tetracycline $250 \mathrm{mg}$ four times a day). The patients were instructed to begin brushing with an end tufted brush on the second postoperative day. Patients were seen seven days after surgery, and the tissues were inspected for material coverage; sutures were not removed. In the event the E-PTFE material was exposed, it was trimmed with sharp scissors. Postoperative examinations were performed for eight consecutive weeks, at which time the tissues were again inspected for coverage of the material. In addition, the teeth were polished with a rubber cup and water.

\footnotetext{
† Hu-Friedy Instrument Co., Chicago, IL.
} 

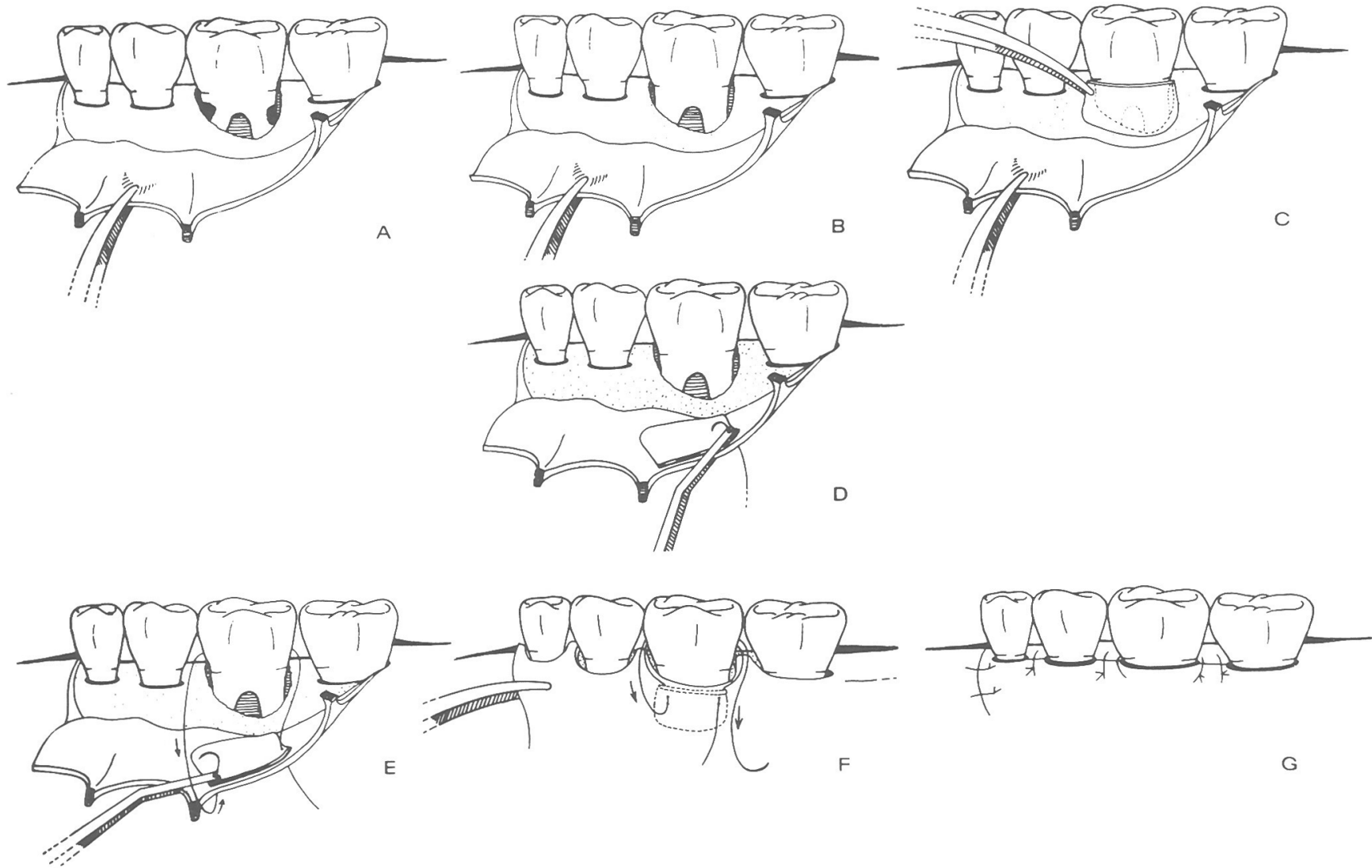

Figure 1. Illustration demonstrates surgical and suturing method for placement of Gore-tex periodontal material. A. Flap is extended two teeth anterior to molar with furcal involvement. B. Root surfaces have been debrided. C. Periodontal material is fitted over defect and root. D. Suture is placed through flap and material. E. Circumferential suture through mesial aspect of flap and material. F. Suture is wrapped around to distal and tied, completely covering material. G. Interrupted sutures placed through interdental papillae and vertical incision.

\section{RESULTS}

The sutures were resorbed between four and seven weeks. In most instances the porous collar became slightly exposed from 18 to 21 days after surgery. Close inspection of the tissues during this period revealed a pink adherent tissue between the root surface and the material. By five weeks the E-PTFE material could usually be removed with a gentle tug. When the material could not be removed easily the tissues were anesthetized, and the E-PTFE material was surgically excised from the flap. The inner margin of the flap was curetted without touching the root surface. The tissue along the root was not disturbed. The flaps were replaced over the newly formed tissue and secured with 4-0 Dexon sutures. Treated sites were not probed for three months.

Case 1 was reentered after three months, Case 2 was reentered after six months, and Case 3 was biopsied after three months. Prior to reentry, probing attachment levels and gingival recession were recorded. Partial thickness incisions were begun in the gingival crevice and extended one tooth anterior to the treated tooth. Short vertical relaxing incisions were used to facilitate flap management. Granulation tissue was removed with sharp curettes, measurements were made, and the area was photographed. The wounds were then closed with 4-0 silk sutures.

After three months of healing, one tooth with adjacent periodontal tissues was removed for histologic study (Case 3). This tooth had been indicated for removal for prosthetic reasons. The tissues were fixed in $10 \%$ neutral buffered formalin, decalcified and embedded in paraffin. Serial sections, $8 \mu$ thick, were cut parallel to the long axis of the tooth. Various sections were stained with hematoxyline and eosin, Van Gieson's stain and Mallory's connective tissue stain.

\section{CASE REPORTS}

Case 1. Prior to initial surgery there was Class III furcation involvement extending to the distal of the maxillary right first molar (Tables 1 and 2, Fig. 2). The initial probing attachment level in the midfurcation area was $10 \mathrm{~mm}$. The defect was measured after debridement. The distance from the cementoenamel junction to the interradicular alveolar crest was $10 \mathrm{~mm}$; the distance from the cementoenamel junction to the base of the defect was $10 \mathrm{~mm}$. The apical width of the defect was $6 \mathrm{~mm}$. Periodontal material was contoured and sutured to the flap using the previously described su- 
Table 1

Case 1. Maxillary right first molar. Clinical measurements (mm) prior to subgingival E-PTFE placement $(A)$ and at reentry three months after placement (B)

\begin{tabular}{llcc}
\hline & \multicolumn{3}{c}{ Midfacial } \\
\cline { 2 - 4 } & Recession & Pocket depth & $\begin{array}{c}\text { Clinical attachment } \\
\text { level }\end{array}$ \\
\hline A & -3 & 7 & 10 \\
B & -4 & 2 & 6 \\
Change & $-1 \mathrm{~mm}$ & $-5 \mathrm{~mm}$ & $+4 \mathrm{~mm}$ \\
\hline
\end{tabular}

Table 2

Case 1. Maxillary right first molar. Advanced furcation involvement. Defect measurements $(\mathrm{mm})$ prior to subgingival E-PTFE placement (A) and "open probing attachment level" at reentry (B) three months later

\begin{tabular}{lcccc}
\hline & \multicolumn{4}{c}{ Midfacial } \\
\cline { 2 - 5 } & CEJ crest & $\begin{array}{c}\text { CEJ } \\
\text { defect base }\end{array}$ & $\begin{array}{c}\text { Horizontal } \\
\text { measure fornix }\end{array}$ & $\begin{array}{c}\text { Horizontal } \\
\text { measure base }\end{array}$ \\
\hline A & 10 & 10 & 10 to distal & 4 \\
B & 5 & 5 & 5 to distal & 0 \\
Change & $+5 \mathrm{~mm}$ & $+5 \mathrm{~mm}$ & $+5 \mathrm{~mm}$ & $+4 \mathrm{~mm}$ \\
\hline
\end{tabular}

turing technique. The material became exposed after 19 days and was removed after 37 days.

The area was reentered three months after surgery. There were $4 \mathrm{~mm}$ of gingival recession, a $6-\mathrm{mm}$ gain of clinical probing new attachment, a 5-mm horizontal gain of "open probing new attachment" and complete closure of the apical aspect of the defect. The tissue was firmly adherent to the root surfaces; however, this tissue did not have the consistency of bone. There were no radiographic changes between the initial surgery and reentry.

Case 2. Prior to initial surgery, the mandibular left cuspid exhibited advanced periodontal disease and was initially given a hopeless prognosis (Tables 3 and 4, Figs 3 and 4). The patient signed a surgical consent form agreeing to a postsurgery biopsy. One-wall vertical defects were located at the mesial and distal interproximal surfaces, and horizontal bone loss was evident on the facial surface. At surgery, a reference measurement groove was placed on the midfacial aspect of the root. The distance from the base of the defect to the top of the groove was $10 \mathrm{~mm}$. The distance from the top of the groove to the cementoenamel junction was $5 \mathrm{~mm}$. Gore-tex periodontal material was secured tightly

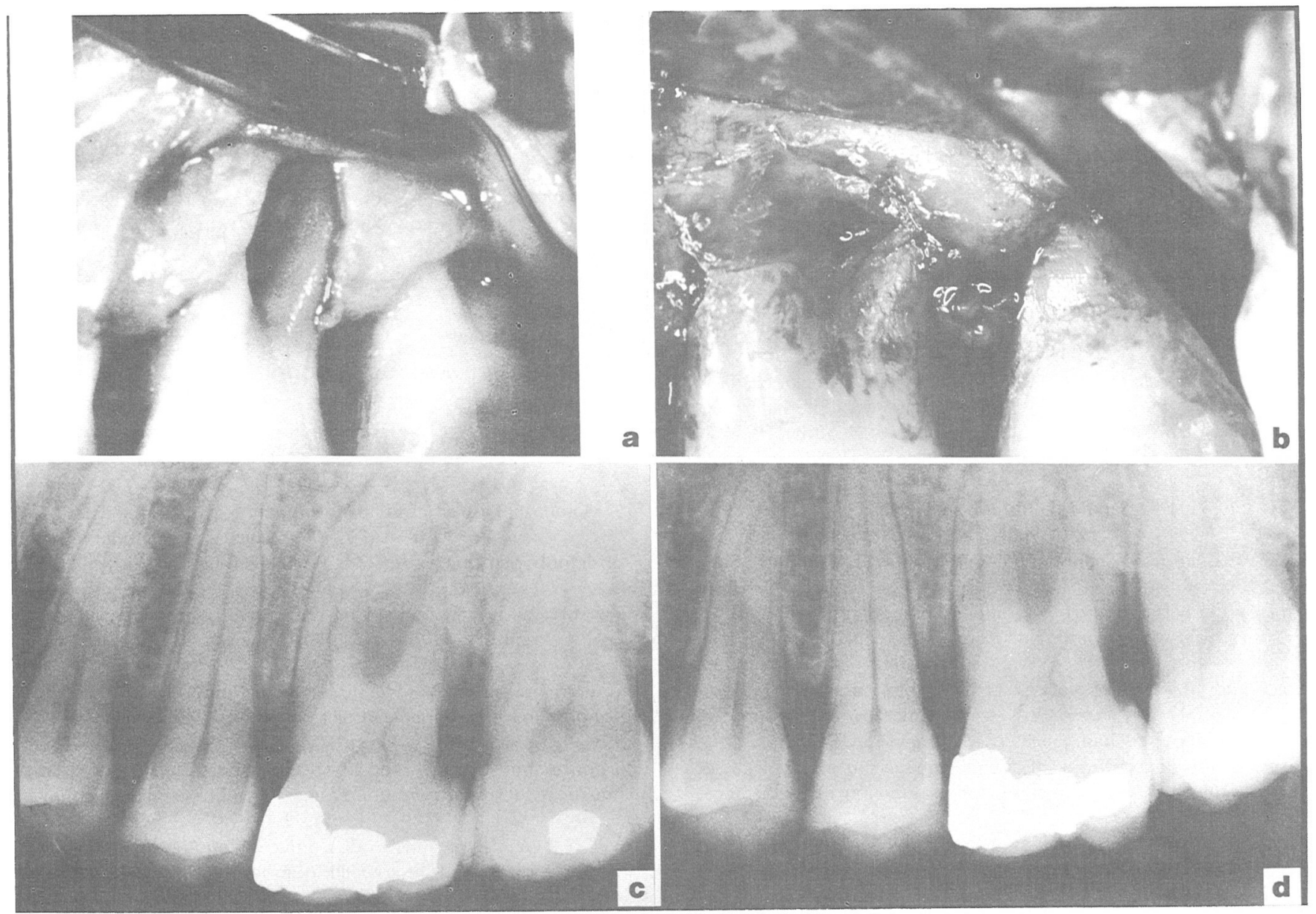

Figure 2. Case 1 a. Maxillary right first molar. Extensive furcation involvement has been debrided. Periodontal material has been sutured to flap. b. Reentry. Base of furcation is closed. Fornix of furcation can be probed $5 \mathrm{~mm}$ to distal. The "open new attachment" is dense and cannot be probed; however, it is not bone. c. and $\mathbf{d}$. initial and reentry radiographs. There were no radiographic changes from surgery to reentry. 
Table 3

Case 2. Mandibular left cuspid. Clinical measurements $(\mathrm{mm})$ prior to subgingival E-PTFE placement $(A)$ and at reentry six months after placement $(B)$

\begin{tabular}{|c|c|c|c|c|c|c|c|c|c|}
\hline & \multicolumn{3}{|c|}{ Recession } & \multicolumn{3}{|c|}{ Pocket depth } & \multicolumn{3}{|c|}{ Attachment level } \\
\hline & $\mathrm{DF}^{*}$ & $\mathrm{~F}$ & MF & DF & $\mathrm{F}$ & MF & DF & $F$ & MF \\
\hline A & -3 & -2 & -2 & 7 & 10 & 10 & 10 & 12 & 12 \\
\hline B & -5 & -7 & -5 & 3 & 1 & 3 & 8 & 8 & 8 \\
\hline Change & $-2 \mathrm{~mm}$ & $-5 \mathrm{~mm}$ & $-3 \mathrm{~mm}$ & $-4 \mathrm{~mm}$ & $-9 \mathrm{~mm}$ & $-7 \mathrm{~mm}$ & $+2 \mathrm{~mm}$ & $+4 \mathrm{~mm}$ & $+4 \mathrm{~mm}$ \\
\hline
\end{tabular}

Table 4

Case 2. Mandibular left cuspid. Changes in bone and "open probing new attachment measurements" (mm) prior to subgingival E-PTFE placement $(A)$ and at reentry six months after placement $(B)$

\begin{tabular}{lccccccc} 
& \multicolumn{3}{c}{ CEJ crest } & & \multicolumn{3}{c}{ CEJ defect base } \\
\cline { 2 - 4 } \cline { 5 - 7 } & DF* & F & MF & & DF & F & MF \\
\hline A & 12 & 15 & 12 & 14 & 15 & 15 \\
B & 9 & 11 & 7 & 9 & 11 & 7 \\
& & & & & & \\
Change & $+3 \mathrm{~mm}$ & $+4 \mathrm{~mm}$ & $+5 \mathrm{~mm}$ & $+5 \mathrm{~mm}$ & $+4 \mathrm{~mm}$ & $+8 \mathrm{~mm}$ \\
\hline
\end{tabular}

*DF, distal facial; F, facial; MF, mesial facial.

around the tooth as previously described. The E-PTFE material became exposed after six weeks and was removed after 12 weeks. At reentry, six months after surgery, $5 \mathrm{~mm}$ of bone-fill on the mesial surface and 8 $\mathrm{mm}$ on the distal surface were noted. There was a 4-mm gain of horizontal "open probing new attachment" on the facial surface. The facial tissue did not have the consistency of bone; however, it was dense and could not be probed. The reentry radiographs demonstrated a slight increase in radiopacity when compared with those taken initially. At reentry the tooth was considered to have a good prognosis, and a biopsy was not performed.

Case 3. This patient had advanced bone loss on the maxillary right first molar (Tables 5 and 6, Fig. 5). The initial clinical attachment level at the midfacial probing point was $7 \mathrm{~mm}$. A two wall defect extended from the buccal surface of the mesial buccal root to the mesial side of the root. The buccal furcation was not affected. Average distance from the cementoenamel junction to the alveolar crest was $4.3 \mathrm{~mm}$, while average defect depth was $8 \mathrm{~mm}$. After the defect and root surfaces were debrided, a notch was made in the root $1 \mathrm{~mm}$ coronal to the most apical depth of the defect. The occlusive cementoenamel material was sutured over the defect and retained for 30 days.

The treated area was biopsied at three months. There were $2 \mathrm{~mm}$ of gingival recession and a $3-\mathrm{mm}$ average gain of clinical probing attachment level. The tissues were anesthetized with local anesthesia, and the mesial buccal root and contiguous tissues were removed for histologic study.

The photomicrographs can be seen in Figure 6. At low magnification (Fig. 6a) the gingival tissues are attached to the tooth. The notch (n) placed during surgery is at the apical end of the root and is approximately $1 \mathrm{~mm}$ coronal to the base of the defect. Bone is present coronal to the notch. Thin junctional epithelium covers dense connective tissue and is located coronal to the notch (junctional epithelium). Slight inflammation is present within the connective tissue but does not appear to affect the tissue adjacent to the junctional epithelium. Between the junctional epithelium and the notch, the connective tissue exhibits a close relationship to the instrumented root surface.

Under higher magnification (Fig. 6b and 6c), the trabecular pattern of new bone formation $(\mathrm{nb})$ is located coronal to the notch. A layer of new cementum (nc), irregular in thickness, was deposited in the notch and extends coronally. The new cementum has an eosinophilic appearance and was deposited on dentin and old cementum. Connective tissue (ct) fibers are evident between the bone and the new cementum. Coronal to the new bone, gingival connective tissue fibers are inserted into newly deposited cementum. Some fibers are also parallel to the root surface. This pattern was found between the apical extent of the junctional epithelium and the coronal extent of the new cementum.

\section{DISCUSSION}

This paper describes a surgical and suturing method for isolating root surfaces during new attachment procedures. The suturing technique is a practical method for placing and retaining subgingival periodontal material. The periodontal material prevents epithelium and gingival connective tissue from contacting the root surface. It also creates a space adjacent to the root. This space may allow cells from the periodontal membrane to repopulate the root. The procedure does not prevent bone or osteogenic cells from entering into the healing process.

Three patients were treated using root isolation for the purpose of new attachment. In two patients (Cases 1 and 2), there was clinical evidence of a coronal gain of new attachment with minimal gingival recession. At reentry, if the new tissue was not bone, it was termed "open probing new attachment." In one patient (Case 3) there was clinical evidence of bone fill after treatment of mesial and distal one wall vertical defects. The facial aspect of this tooth had a horizontal increase in "open clinical new attachment." A biopsy of a site treated 


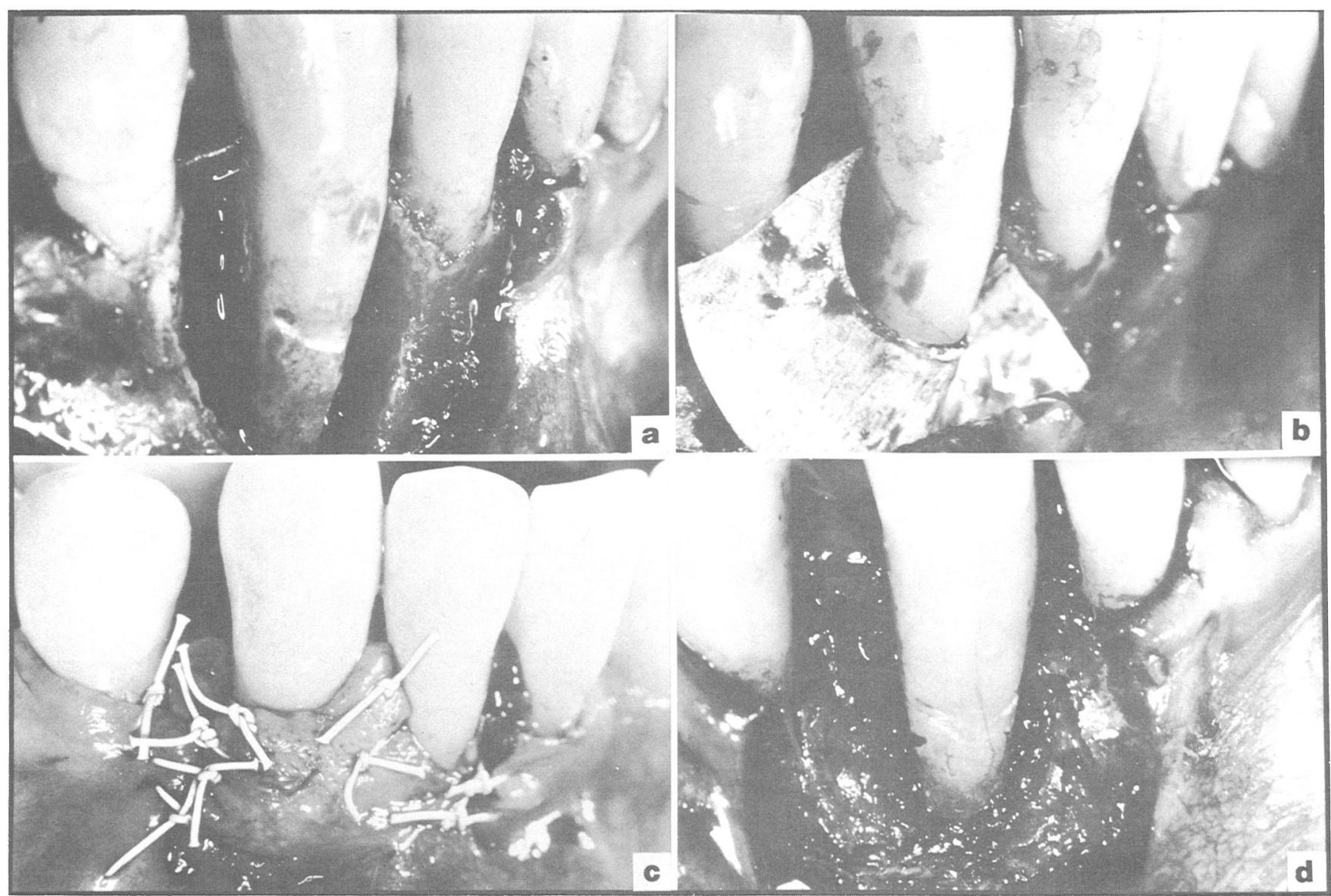

Figure 3. a. Debridement of defects adjacent to the mandibular right cuspid. b. Periodontal material has been adjusted to isolate the root. c. Peridontal material has been sutured to the flap. $\mathbf{d}$. The site was reentered six months after surgery. Note horizontal "open new attachment" on the facial aspect.

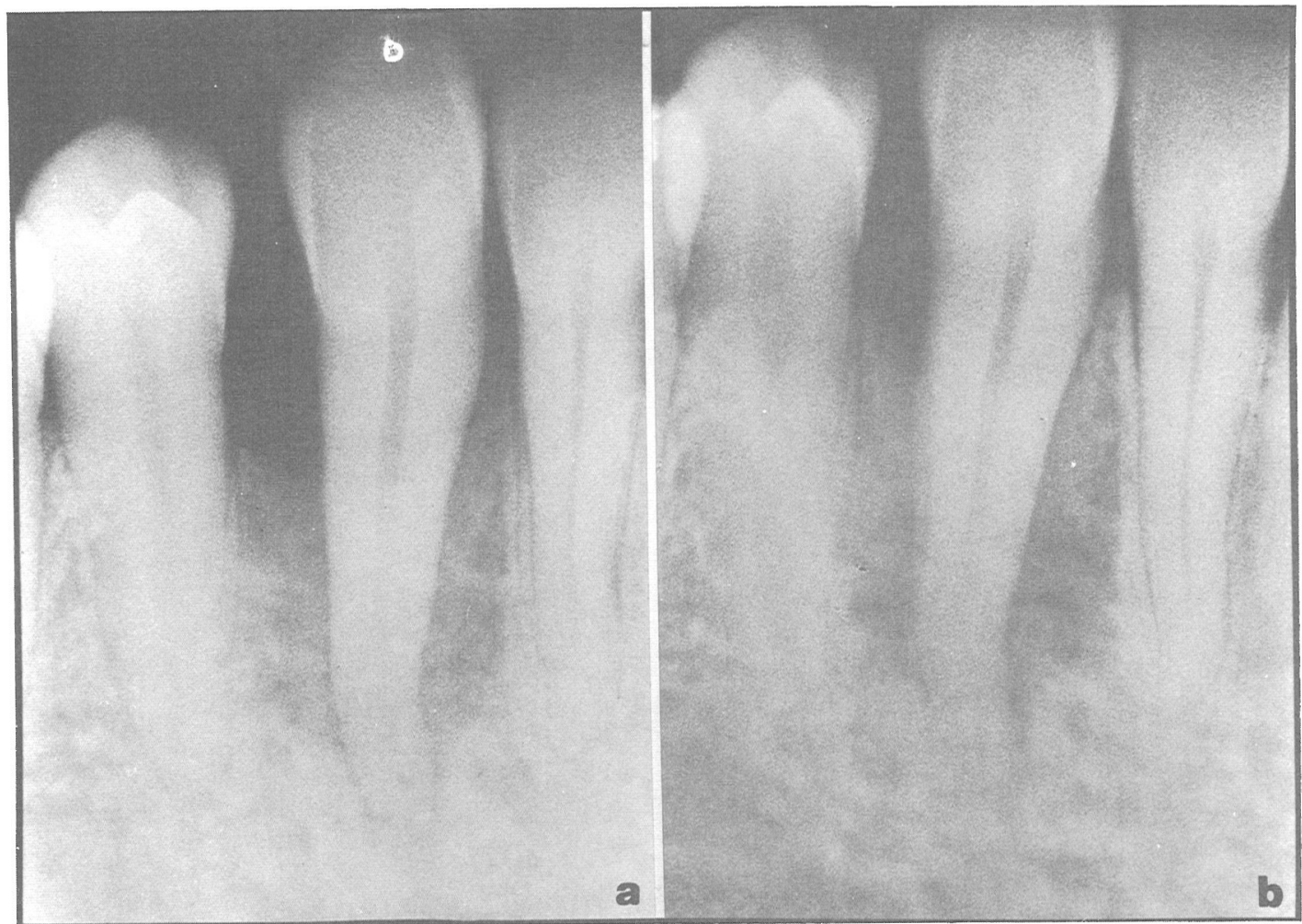

Figure 4. a. Preoperative radiograph of the mandibular left.cuspid. b. Radiograph taken at six months' reentry. Slight increase in radiopacity when compared with initial radiograph. 
Table 5

Case 3. Maxillary right first molar. Measurements $(\mathrm{mm})$ prior to subgingival E-PTFE placement $(A)$ and at time of biopsy (B)

\begin{tabular}{|c|c|c|c|c|c|c|}
\hline & \multicolumn{2}{|c|}{ Recession } & \multicolumn{2}{|c|}{ Probing depth } & \multicolumn{2}{|c|}{ Attachment level } \\
\hline & $F^{*}$ & MF & $F$ & MF & $\mathrm{F}$ & MF \\
\hline A & 0 & 0 & 7 & 6 & 7 & 6 \\
\hline B & -2 & -2 & 1 & 2 & 3 & 4 \\
\hline Change & $-2 \mathrm{~mm}$ & $-2 \mathrm{~mm}$ & $-6 \mathrm{~mm}$ & $-4 \mathrm{~mm}$ & $+4 \mathrm{~mm}$ & $+2 \mathrm{~mm}$ \\
\hline
\end{tabular}

${ }^{*} \mathrm{~F}$, facial; MF, midfacial.

Table 6

Case 3. Mesial buccal root of maxillary right first molar. Measurements ( $\mathrm{mm}$ ) prior to subgingival material placement $(A)$

\begin{tabular}{cccccccc}
\hline & \multicolumn{3}{c}{ CEJ crest } & & \multicolumn{3}{c}{ CEJ defect base } \\
\cline { 2 - 4 } \cline { 6 - 7 } \cline { 5 - 7 } & $\mathrm{DB}^{*}$ & $\mathrm{MB}$ & Mes & DB & MB & Mes \\
\hline A & 3 & 5 & 5 & 7 & 8 & 9 \\
B & \multicolumn{3}{c}{ Tooth removed for biopsy } \\
\hline
\end{tabular}

*DB, distal buccal; MB, midbuccal; Mes, mesial buccal.

with the periodontal material demonstrated new cementum, bone and periodontal fibers coronal to the reference notch. The evidence from the biopsy strongly suggests that new attachment is achievable.

The biologic basis for new attachment has been documented by Nyman et al. ${ }^{11,17}$ and Gottlow et al. ${ }^{18}$ Gottlow et al. ${ }^{18}$ demonstrated new attachment in humans after membranes were placed over vertical and furcation defects. The histologic findings reported by Gottlow revealed new cementum with inserting fibers on previously diseased roots. The teflon membranes used covered the defects and roots and extended occlusally through the gingival crevice. This placement of membranes through the gingival crevice may have the potential for oral hygiene problems. Furthermore, there is also a possibility of membrane dislodgement due to gingival trauma.

For the above reasons a suturing technique that would allow for subgingival material placement was developed. The Gore-tex periodontal material used in this project appeared to be an appropriate material for subgingival root and defect isolation. The suturing technique securely adapts the flap and material to the root surface. Between the third and fourth postoperative weeks, the sutures resorbed, and exposure of the gingival collar occurred. Since the gingiva will not grow into the periodontal material, once the sutures resorb, the material can move coronally. This, together with slight gingival recession, allowed for exposure of the periodontal material. If more than $1 \mathrm{~mm}$ of material is exposed, it is advisable to trim the exposed part with sharp scissors. Plaque accumulates in the exposed gingival collar. It is very important that the gingival tissues and exposed E-PTFE be carefully cleaned by the patient. End-tufted brushing is recommended. Patients are discouraged from using dental floss while the material is in place since it may loosen or cut the sutures causing premature exfoliation of the material. By the

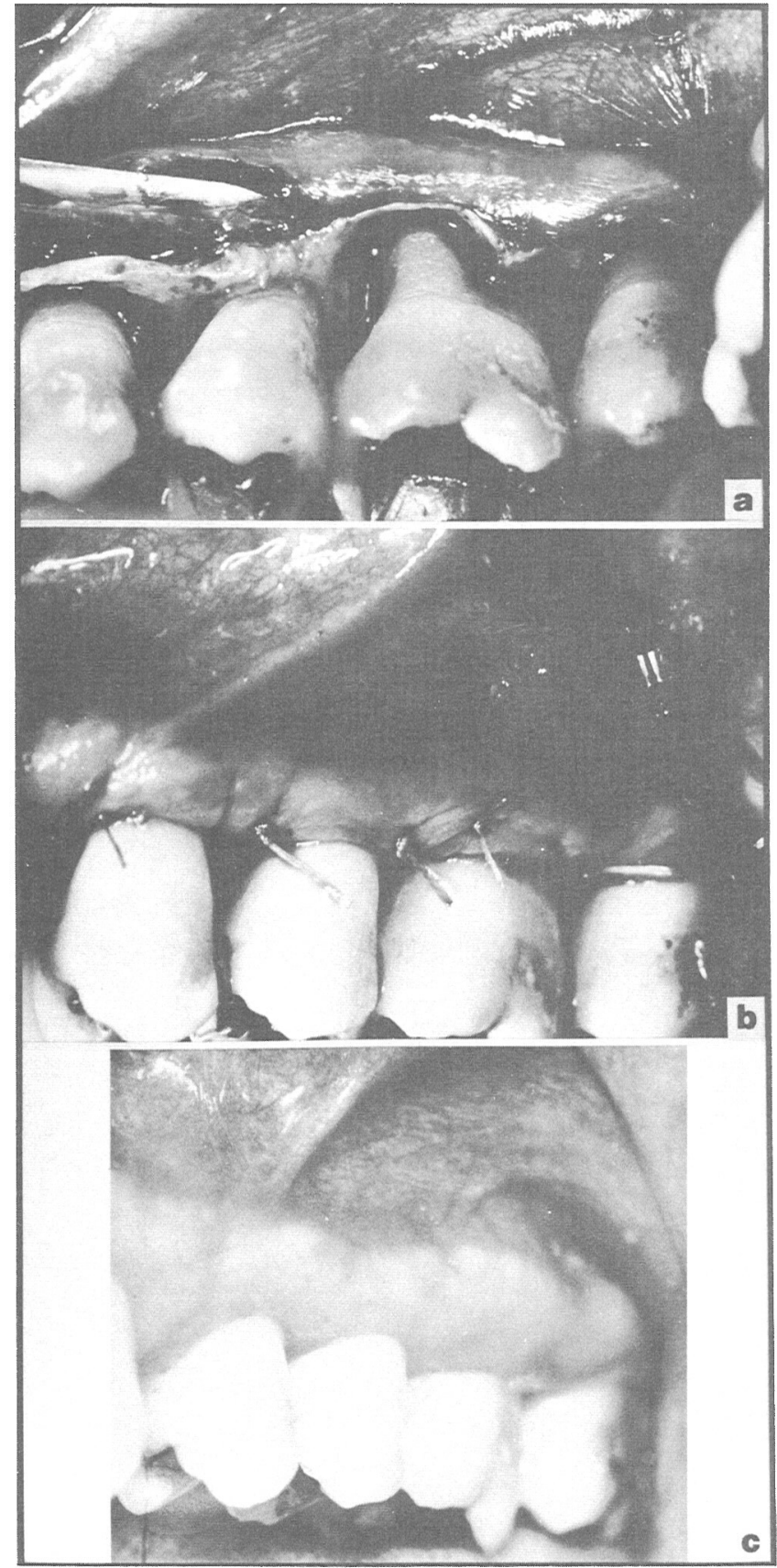

Figure 5. a. Maxillary right first molar. Two-wall defect after debridement. b. Material has been sutured in place. c. Appearance of tissues prior to biopsy of mesial buccal root three months after surgery.

fourth postoperative week, a pink, adherent tissue is frequently seen between the root and the inner aspect of the material. This tissue should not be probed for three months. The material should be removed within four to six weeks after placement. This can be done as a minor surgical procedure.

The long-term stability and predictability of clinical new attachment as a result of root isolation is unknown. Three-month evaluation of new attachment procedures may be too early to determine bone regeneration. The clinical findings presented in this paper support those of Nyman et al. ${ }^{17}$ and Gottlow et al. ${ }^{18}$ They provide evidence that clinical and histologic new attachment is 


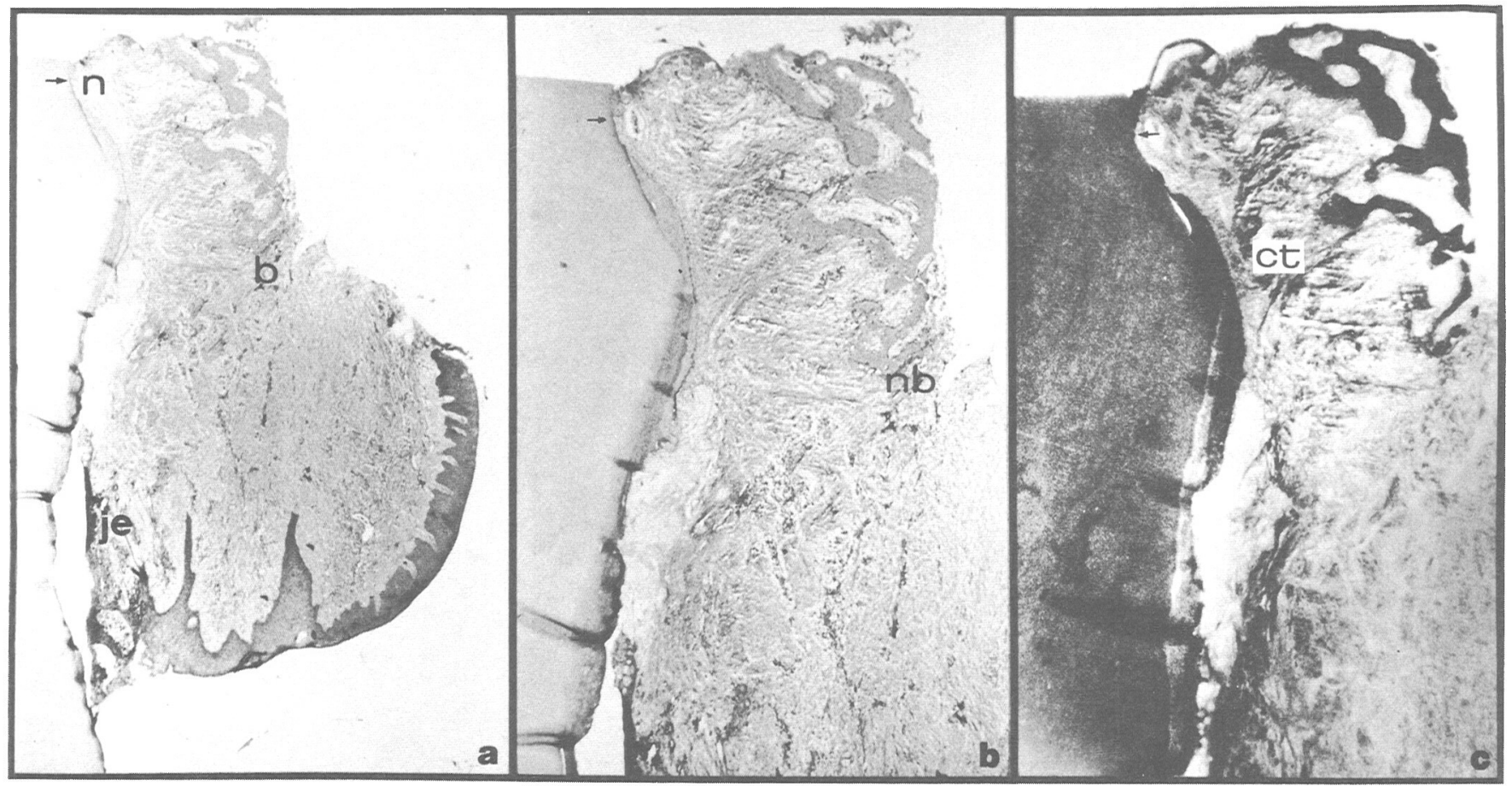

Figure 6. a. Histologic section of mesial buccal root taken from the maxillary right first molar. Notch (n arrow) was placed 1 mm coronal to the base of the defect. je, junctional epithelium. Bone $(\mathrm{b})$ is coronal to the notch (arrow) (magnification $\times 25)$. b. New bone (nb) formation is present coronal to the notch (arrow). New cementum $(\mathrm{nc})$ is deposited on old cementum and dentin (magnification $\times 45$ ). c. Connective tissue fibers (ct) are inserting into newly deposited cementum (magnification $\times 100$ ).

possible on previously diseased roots. Further studies are needed to evaluate the predictability and long-term stability of new attachment procedures. Studies are also needed to determine the appropriate time for removal of the Gore-tex material and to determine the role of bone in the healing process.

\section{ACKNOWLEDGMENTS}

We wish to thank Dr. Jan Gottlow for the histologic preparation of the biopsy and Dr. Clifford Ochsenbein for his help in reviewing the manuscript.

\section{REFERENCES}

1. Prichard, J.: The infrabony technique as a predictable procedure. J Periodontol 28: 202, 1957.

2. Bjorn, J.: Experimental studies on reattachment. Dent Pract 11: $351,1961$.

3. Ellegard, B., Karring, T., and Löe, H.: New periodontal attachment procedure based on retardation of epithelial migration. $J$ Clin Periodontol 1: 75, 1974.

4. Melcher, A. H.: On the repair potentials of the periodontal tissues. J Periodontol 47: 256, 1978.

5. Boyko, G., Melcher, A. H., and Brunette, D. M.: Formation of new periodontal ligament by periodontal ligament cells implanted in vivo after culture in vitro. J Periodont Res 16: 73, 1981.

6. Karring, T., Nyman, S., and Lindhe, J.: Healing following implantation of periodontitis affected roots into bone tissue. $J$ Clin Periodontol 7: 96, 1980.

7. Nyman, S., Karring, T., Lindhe, J., and Stoffan, P.: Healing following implantation of periodontitis affected roots into connective tissue. J Clin Periodontol 7: 394, 1980.

8. Karring, T., Nyman, S., Lindhe, J., Sirirat, M.: Potentials for root resorption during periodontal wound healing. J Clin Periodontol 11: $41,1984$.

9. Caton, J., and Nyman, S.: Histometric evaluation of periodontal surgery. J Clin Periodontol 7: 224, 1980.
10. Stahl, S. S., Froum, S. J., and Kushner, L.: Healing responses of human intraosseous lesions following the use of debridement, grafting and citric acid root treatment. II. Clinical and histological observations: one year postsurgery. J Periodontol 54: 325, 1983.

11. Nyman, S., Gottlow, J., Karring, T., and Lindhe, J.: The regenerative potential of the periodontal ligament. An experimental study in the monkey. J Clin Periodontol 9: 275, 1982.

12. Aukhil, I., Simpson, D. M., and Schaberg, T. V.: An experimental study of new attachment procedure in beagle dogs. J Periodont Res 18: 643, 1983.

13. Magnusson, I., Nyman, S., Karring, T., and Egelberg, J.: Connective tissue attachment formation following exclusion of gingival connective tissue and epithelium during healing. $J$ Periodont Res 20: 201, 1985.

14. Aukhil, I., Pettersson, E., and Suggs, C.: Guided tissue regeneration. An experimental procedure in beagle dogs. $J$ Periodontol 57: 727, 1986.

15. Card, S., Smith B., Caffesse, R., et al.: New attachment following the surgical treatment of periodontitis in dogs (Abstr.). $J$ Dent Res 1987.

16. Caffesse, R., Smith, B., Castelli, W., and Nasjleti, C.: New attachments achieved by guided tissue regeneration in beagle dogs (Abstr.). J Dent Res 1987.

17. Nyman, S., Lindhe, J., Karring, T., and Rylander, H.: New attachment following surgical treatment of human periodontal disease. J Clin Periodontol 8: 249, 1982.

18. Gottlow, J., Nyman, S., Karring, T., and Wennstrom, J.: New attachment following surgical treatment of human periodontal disease. J Clin Periodontol 13: 604, 1986.

19. Glickman, I.: Clinical Periodontology, 2nd ed, pp 694-696. Philadelphia, W. B. Saunders Co., 1958.

20. Dahlberg, W. H.: The Dental Clinics of North -America, vol 13, pp 149-158. Philadelphia, W. B Saunders Co., 1969.

21. Gottlow, J., Karring, T., and Nyman, S.: Guided tissue regeneration following the use of Gore-tex (Abstr.). J Dent Res, 1987.

Send reprint requests to: William Becker, DDS, $801 \mathrm{~N}$. Wilmot B-2, Tucson, AZ 85711. 